\title{
O PROGRAMA MAIS EDUCAÇÃO EM MARINGÁ: apontamentos iniciais da proposta burguesa de educação integral
}

\author{
Marco Antônio de Oliveira Gomes ${ }^{1}$
}

\section{RESUMO}

O presente artigo tem por objetivo identificar historicamente a construção das propostas de educação integral, suas respectivas matrizes e analisar as propostas em curso no município de Maringá. Trata-se de uma análise documental, bibliográfica e de levantamento de dados fundamentada no materialismo histórico e dialético, que se expressa na Pedagogia Histórico-Crítica. O artigo aponta para os limites das propostas em curso que incorporam ações marcadas pela descontinuidade com destaque para a redução da responsabilidade do Estado diante da educação básica.

Palavras-chave: Programa Mais Educação. Tempo Integral. Educação integral.

\section{THE MORE EDUCATION PROGRAM IN MARINGÁ: initial proposal bourgeois notes of integral education}

\section{ABSTRACT}

The purpose of this article is to identify historically the construction of proposals for integral education, their respective headquarters and to analyze the proposals under way in the municipality of Maringá. It is a documentary, bibliographical and data analysis analysis based on historical and dialectical materialism, which is expressed in Historical Critical Pedagogy. The article points to the limits of the current proposals that incorporate actions marked by the discontinuity, highlighting the reduction of state responsibility towards basic education.

Keywords: More Education Program. Integral Time. Integral Education.

\section{EL PROGRAMA MÁS EDUCACIÓN EN MARINGÁ: apuntes iniciales de la propuesta burguesa de educación integral}

\section{RESUMEN}

El presente artículo tiene por objetivo identificar históricamente la construcción de las propuestas de educación integral, sus respectivas matrices y analizar las

1 Doutorado (2008) em História e Filosofia da Educação pela Universidade Estadual de Campinas (Unicamp). Professor adjunto da Universidade Estadual de Maringá, lotado no Departamento de Fundamentos da Educação. E-mail: marcooliveiragomes@yahoo.com.br 
propuestas en curso en el municipio de Maringá. Se trata de un análisis documental, bibliográfico y de relevantamiento de datos fundamentado en el materialismo histórico y dialéctico, que se expresa en la Pedagogía Histórico Crítica. El artículo apunta a los límites de las propuestas en curso que incorporan acciones marcadas por la discontinuidad con destaque para la reducción de la responsabilidad del Estado ante la educación básica.

Palabras clave: Programa Más Educación. Tiempo Integral. Educación integral.

\section{INTRODUÇÃO}

A bandeira da Educação Integral não é uma bandeira nova entre nós. Ao longo da história, a defesa da formação integral foi encampada por intelectuais com perspectivas epistemológicas diferenciadas. Diga-se, as diferentes proposições sobre a formação integral do homem foram forjadas em função dos projetos de classes em disputa. Por isso, nenhuma proposta educacional deve ser compreendida desvinculada da realidade material em que foi forjada, nem apresentada enquanto uma proposição "neutra".

Diante do exposto, o presente artigo tem como propósito identificar e analisar as formas de materialização de Educação Integral no município de Maringá em um cenário marcado pelo crescente avanço das reformas neoliberais.

Para atingirmos os objetivos propostos, foram analisados os documentos pertinentes ao processo de implantação do Programa Mais Educação, que balizaram as ações do poder público no município, além da coleta de dados, ainda em estágio inicial, por meio de uma pesquisa de campo.

O levantamento dos dados disponíveis sinaliza que a proposta desenvolvida contribui para a delegação de responsabilidades do poder público à sociedade civil, apresentada de forma genérica nos documentos, ao mesmo tempo que o trabalho na escola é sobrecarregado com tarefas para as quais nem sempre há condições materiais para a realização.

Acrescente-se que as transformações nas relações de trabalho, as reformas educacionais e os modelos pedagógicos oriundos das condições concretas de trabalho docente provocaram inúmeras mudanças. A expansão das demandas por educação e o crescimento no atendimento 
nem sempre ocorreu de forma a oferecer as condições necessárias para o funcionamento adequado das escolas.

Sinteticamente é possível afirmar que nos últimos três decênios do século XX ocorreram transformações expressivas na dinâmica das relações entre capital e trabalho. Com dimensões e contornos diferentes, as formações sociais geridas pelo modo de produção capitalista sofreram fortes impactos diante da crise estrutural que eclodiu a partir dos anos 1970.

$\mathrm{Na}$ questão específica do mundo do trabalho, a inserção da microeletrônica, robótica e informática, além das novas formas de organização empresarial, passaram a exigir um novo perfil de trabalhador, exigindo para a sua formação novos atributos, cabendo, assim, à educação adequar seu trabalho pedagógico às demandas do mercado. Não por acaso, diante do novo cenário, verifica-se a exigência de outro padrão de escolarização, além de um "novo" professor.

Segundo Gasparini, Barreto e Assunção (2005), o papel do professor nos últimos anos extrapolou a mediação do processo de transmissão do conhecimento, ampliando suas atividades profissionais para além da sala de aula. O professor, além do trabalho que lhe é pertinente em sala, participa de uma série de outras atividades vinculadas à gestão, planejamento, atendimento às famílias e a comunidade.

Embora o sucesso da educação dependa do perfil do professor, a administração escolar não fornece os meios pedagógicos necessários à realização das tarefas, cada vez mais complexas. Os professores são compelidos a buscar, então, por seus próprios meios, formas de requalificação que se traduzem em aumento não reconhecido e não remunerado da jornada de trabalho (GASPARINI; BARRETO; ASSUNÇÃO, 2005, p. 191).

Isto posto, a compreensão desse fenômeno não pode ocorrer de forma isolada da totalidade das relações sociais. A partir da epistemologia do materialismo histórico e dialético, é possível compreender que a educação escolar reflete as contradições engendradas em uma sociedade de classes. 
O fato, portanto, é o seguinte: indivíduos determinados, que como produtores atuam de um modo também determinado, estabelecem entre si relações sociais e políticas determinadas. É preciso que, em cada caso particular, a observação empírica coloque necessariamente em relevo - empiricamente e sem qualquer especulação ou mistificação - a conexão entre a estrutura social e política e a produção. A estrutura social e o Estado nascem constantemente do processo da vida de indivíduos determinados, mas destes indivíduos não como podem aparecer na imaginação própria ou alheia, mas tal e como realmente são, isto é, tal e como atuam e produzem materialmente e, portanto, tal e como desenvolvem suas atividades sob determinado limites, pressupostos e condições materiais, independentemente de sua vontade (MARX, ENGELS, 1984, p. 35-36).

A investigação do fenômeno implica em um esforço de apropriação, pelo pensamento, das determinações que forjaram o objeto, o que implica em uma análise radical antes de sua exposição metódica. A exposição, ou o método de exposição, não deverá ser simplesmente uma exposição do objeto em si, mas é uma exposição que considere as contradições que o constituem. Trata-se de uma exposição que se demonstre um processo marcado pelas contradições de uma sociedade marcada pelos antagonismos de classe. Em outras palavras, significa reconstruir criticamente, no plano ideal, o movimento dialético do fenômeno, pois este não é dado pela experiência direta.

Por isso, não tem sentido estudar um fenômeno por ele mesmo, isolado das relações sociais. Há que se verificar os vínculos do objeto com as formas pelas quais os homens produzem sua existência e com as lutas travadas no interior de uma sociedade de classes. A respeito do tema, Castanha apresenta as seguintes contribuições:

A história foi/é construída por ações individuais e coletivas, entretanto, nem as ações individuais, nem as coletivas se explicam isoladamente. Elas são expressão das condições de existência, das tensões e contradições sociais presentes em um determinado contexto. A história não foi/é feita por homens iluminados, mas sim por sujeitos históricos (CASTANHA, 2013, p. 365).

Assim, cada modelo de escola ou de proposta pedagógica deve ser compreendida em seu tempo e não como uma ação de um indivíduo 
iluminado. A história da educação passa necessariamente pelas lutas políticas e ideológicas de seu tempo.

Por fim, as análises aqui reunidas procuram contemplar, ao menos três aspectos importantes: o movimento operário e a proposta de educação integral no Brasil; a educação integral e o movimento da escola nova no Brasil; e as formas de materialização da educação integral no município de Maringá.

\section{BREVE SíNTESE DO MOVIMENTO OPERÁRIO E A EDUCAÇÃo NO ALVORECER DA REPÚBLICA NO BRASIL}

Ao longo da República Velha (1889-1930), a classe trabalhadora vivia excluída do acesso a uma série de direitos. Não obstante, ainda que formalmente, vivia-se em um regime de aparência "democrática", na realidade, nem todos brasileiros estavam aptos a exercer o simples direito de voto, uma vez que a Constituição de 1891 impedia a participação dos analfabetos e das mulheres. Dessa forma, em um país com aproximadamente $75 \%$ da população iletrada, a participação política era um direito de poucos. No âmbito dos direitos sociais, em especial na questão dos direitos do trabalho, estes não existiam na Carta de 1891, demonstrando que a herança do passado escravocrata se fazia presente nas relações entre o capital e trabalho.

Em relação às condições de trabalho nas fábricas, é possível afirmar que a precariedade era uma característica marcante, assemelhando-se em verdadeiros "presídios industriais". A jornada de trabalho, com a ausência de descanso semanal, chegava a 12 horas diárias, sendo em muitos casos ultrapassada.

O operário, habituado à servidão, com medo de perder o escasso pão penosamente ganho, humilha-se, ou contradiz o que antes afirmou, ou ainda pior, faz-se solidário com o patrão ou contramestre, em declarações de jornal ou em manifestações públicas (CARONE, 1984, p. 51).

A opressão imposta aos trabalhadores era uma decorrência das circunstâncias materiais que privava-os das condições mínimas de 
existência. Nesse aspecto, o Estado, como em qualquer sociedade de classes, atendia as demandas dos grupos dominantes.

Nesses termos, o projeto republicano implementado em 1889 possuía um caráter fundamentalmente elitista. Durante a República Velha, não havia uma legislação que regulasse as relações entre o capital e o trabalho. O que melhor sintetizou a atuação política do Estado brasileiro frente à classe operária foi a famosa frase atribuída ao último presidente Whashington Luís: "A questão social é caso de polícia". Em outras palavras, naquele cenário, a intervenção do Estado na questão social resumia-se à repressão policial contra as manifestações operárias.

No entanto, em decorrência do crescimento das atividades industriais, o que não impediu a manutenção do caráter agrário-exportador de nossa economia, verifica-se o crescimento da quantidade de trabalhadores fabris ao mesmo tempo que forja-se o embrião das lutas operárias. Esse crescimento se fez, em grande medida, por meio da chegada de imigrantes que deixavam seus respectivos países em busca de condições melhores de sobrevivência no Brasil em um momento de crise do escravismo e, posteriormente, abolição da escravidão. Lembre-se que alguns dos imigrantes eram operários em suas respectivas nações de origem e participavam de atividades sindicais que se desenvolveram na segunda metade do século XIX.

Já no Brasil, a maioria dos imigrantes se depararam com condições deploráveis de trabalho e existência. No âmbito da educação escolar, em um país de analfabetos, poucos tinham acesso, nas origens do regime republicano. Trata-se de uma escola destinada a poucos, que pelo conteúdo e método do que difundia, produzia a materialização dos valores aceitos e defendidos pelas classes dominantes.

Diante dessas circunstâncias, as lideranças operárias desde cedo compreenderam que o quadro de analfabetismo que imperava no Brasil era um enorme obstáculo a organização dos trabalhadores. Em um primeiro momento, a corrente socialista liderou as reivindicações em defesa da laicidade da educação escolar e de recursos públicos para a construção e 
manutenção de escolas. Do ponto de vista pedagógico, os resultados não foram significativos o suficiente para a elevação cultural e política dos trabalhadores. No entanto, faz-se importante assinalar que pela primeira vez em nossa história esboçava-se uma proposta de educação com o propósito de formação política do proletariado urbano na luta pela superação das condições materiais a que estavam submetidos os trabalhadores.

No contexto das lutas travadas entre capital e trabalho do início do século XX, outros grupos surgiram e conquistaram espaço em defesa dos trabalhadores. Trata-se dos anarquistas. As lideranças, em sua maioria, constituíam-se de trabalhadores oriundos do continente europeu. O analfabetismo também foi visto pelos anarquistas como o grande obstáculo ao desenvolvimento da luta operária contra o capital e o Estado.

O movimento educacional organizado pelos libertários brasileiros nos anos iniciais do século XX, espelhava-se no movimento anarquista espanhol, onde Ferrer y Guardia sistematizava as bases da educação anarquista. Em decorrência da defesa da autogestão como instrumento de uma democracia efetiva, os anarquistas propunham a ação direta a partir da consciência de classe. Nesse aspecto se estreitam os laços entre os objetivos libertários e uma pedagogia fundamentada nos princípios da liberdade. Por isso, colocavam-se em uma posição contrária a obrigatoriedade da educação ao mesmo tempo que combatiam a Igreja e o Estado, entendidos como instituições a serviço dos capitalistas. Dessa forma, propugnaram pela criação de escolas livres tanto das igrejas quanto do Estado.

As escolas organizadas pelos anarquistas nos primeiros anos do século XX, receberam a denominação de Escolas Modernas ou Escolas Racionalistas, destinadas fundamentalmente aos filhos de operários e de trabalhadores em geral, eram pautadas pelos seguintes princípios pedagógicos de uma educação:

a) integral, por meio do vínculo entre atividades manuais e intelectuais, que possibilitasse o desenvolvimento progressivo e equilibrado do ser humano; 
b) racional, alicerçada na razão, no conhecimento científico e livre de dogmas;

c) mista, ou seja, o princípio da coeducação dos sexos;

d) solidária, com o propósito de desenvolver práticas libertárias e de respeito ao homem.

Nesses termos, as escolas anarquistas defendiam uma educação que subsidiasse o trabalhador com conhecimentos científicos necessários às lutas travadas contra a opressão. Por isso, as escolas anarquistas não se limitavam apenas ao ensino formal para as crianças oriundas das classes trabalhadoras, ofertando também para os adultos o ensino profissional.

Nesse sentido, para a pedagogia anarquista, a ciência e a liberdade são instrumentos fundamentais para a promoção das mudanças básicas na estrutura social e no combate ao Estado por incentivar a cooperação entre homens livres.

\section{A PERSPECTIVA LIBERAL BURGUESA DE EDUCAÇÃO INTEGRAL}

Para além da proposta da educação libertária, correntes do pensamento liberal e do fascismo tupiniquim, denominado como movimento integralista, também levantaram a tese da educação integral.

No Brasil, a compreensão da maneira pela qual a concepção de educação integral se desenvolve passa obrigatoriamente pelo estudo do pensamento educacional das décadas de 20 e 30 do século XX. No Brasil, a compreensão da maneira pela qual a concepção de educação integral se desenvolve passa obrigatoriamente pelo estudo do pensamento educacional das décadas de 20 e 30 do século XX. A educação integral, significando uma educação escolar ampliada em suas tarefas sociais e culturais, esteve presente nas propostas das diferentes correntes políticas que se delinearam naquele período. As correntes autoritárias e elitistas a encamparam com o sentido de ampliação do controle social e dos processos de distribuição criteriosa dos indivíduos nos segmentos hierarquizados da sociedade. O extremo dessa tendência expressouse na concepção de educação integral da Ação Integralista Brasileira. Já as correntes liberais encampavam a educação integral com o objetivo de reconstrução das bases sociais para 0 desenvolvimento democrático, o qual só poderia se dar a partir de indivíduos intencionalmente formados para a cooperação e a participação. Entre os liberais, destaca-se o nome de Anísio Teixeira, por sua significativa elaboração teórica e técnica, visando à 
ampliação das funções da escola e o seu fortalecimento como instituição (CAVALIERE, 2010, p. 249).

No âmbito das propostas liberais, é possível afirmar que a educação é entendida como um instrumento de equalização social, e de adequação dos indivíduos na sociedade moderna e industrial. Trata-se, de uma perspectiva que associa o desenvolvimento econômico e a própria democracia ao processo de universalização da educação.

Como aponta Cavaliere, Anísio Teixeira foi um intelectual de destaque entre os educadores envolvidos com o movimento da escola nova e um propugnador da educação integral. Teixeira partia de uma compreensão idealística de democracia que se fundamentava na igualdade de oportunidades associada à meritocracia. Dessa maneira, acreditava ser possível combater os privilégios no Brasil por meio da educação e, em especial, pela escola.

Dia a dia, torna a nação maior e mais intensa com consciência de si mesma, de seus problemas, de suas contradições, de suas desigualdades, de seus diferentes níveis e modos de viver, de suas distâncias físicas e psicológicas, de sua pobreza e de sua riqueza, do seu progresso e do seu atraso, e, reunindo todas as suas forças, prepara-se para uma nova integração, em um grande esforço de reconstrução e desenvolvimento. Nesse processo de reconstrução, nenhum problema é mais essencial que o da escola, pois por ela é que se efetivará o novo senso de consciência nacional e se afirmará a possibilidade de se fazer permanente e progressiva a grande mobilização do esforço brasileiro (TEIXEIRA apud MOLL, 2012).

De fato, o ideário renovador presente na produção de Teixeira deve ser compreendido em um cenário histórico marcado pela crítica ao ensino tradicional e na consolidação da crença na escola como instituição responsável pelo progresso social e pela posição social dos indivíduos. Entre os anos 20 e 30 do século XX, a bandeira da educação integral foi empunhada pelas dissidências das oligarquias, por intelectuais representantes das camadas médias, além, é claro, de segmentos do movimento operário. Naquele cenário, o movimento da Escola Nova incorporava as reivindicações educacionais populares, sem romper com os alicerces de sustentação da ordem econômica. 
No Manifesto dos Pioneiros da Educação Nova, publicado em 1932, a escola integral e única era apresentada como antítese à escola tradicional.

\begin{abstract}
Mas, do direito de cada indivíduo à sua educação integral, decorre logicamente para o estado que o reconhece e o proclama, o dever de considerar a educação, na variedade de seus gráos e manifestações como uma função social e eminentemente pública, que ele é chamado a realizar, com a cooperação de todas as instituições sociaes. A educação que é uma das funções de que a família se vem despojando em proveito da sociedade política, rompeu os quadros do communismo familial e dos grupos específicos (instituições privadas), para se incorporar definitivamente entre a funcções essenciaes e primordiaes do Estado (MANIFESTO DOS PIONEIROS DA EDUCAÇÃO, 1932).
\end{abstract}

Incumbe enfatizar que a proposição de educação integral, defendida pelo movimento renovador, se amparava na orientação político-filosófica da concepção humanista moderna, pautada no ideal da crença do progresso da ciência, do racionalismo científico e da democracia, concebendo o homem como um ser integral (GOMES, LÔBO, FERRAZZO, 2016, p. 106). Anísio Teixeira, por exemplo, defendeu a implementação de um sistema público de ensino que:

[...] seu programa completo de leitura, aritmética e escrita, e mais ciências físicas e sociais, e mais artes industriais, desenho, música, dança e educação física [...] saúde e alimento à criança, visto não ser possível educá-la no grau de desnutrição e abandono em que vive.

[...] que a escola eduque, forme hábitos, forme atitudes, cultive aspirações, prepare, realmente, a criança para a sua civilização esta civilização tão difícil por ser uma civilização técnica e industrial e ainda mais difícil e complexa por estar em mutação permanente (TEXEIRA, 1959, p.79).

As propostas de Anísio Teixeira indicam sua percepção de educação integral, no qual as crianças deveriam receber uma formação completa, fundamentada em atividades artísticas, físicas, intelectuais, profissionais, de saúde, além do aspecto voltado para a formação de hábitos e atitudes. Em outras palavras, a função da escola ultrapassa a mera transmissão dos conteúdos, avançando para o aspecto da formação integral do aluno. Ressalte-se que trata-se de uma bandeira que perpassa toda a literatura educacional produzida por Teixeira. Assim, cabe enfatizar que sua proposta 
para a educação não pode ser desvinculada do ideário marcado pela industrialização que atravessou o país, principalmente após a Revolução de 1930.

Atente para o fato de que é possível identificar outras manifestações e experiências proclamadas como educação integral, destacando-se o Centro Educacional Carneiro Ribeiro, inaugurado em 1950, arquitetado por Anísio Teixeira, que defendia a criação de oportunidades para que os educandos vivenciassem, por meio da experiência, o modo de vida democrático, como forma de assegurar a própria democracia e o desenvolvimento.

A experiência da escola organizada por Teixeira serviu de inspiração para outras que foram organizadas posteriormente, com destaque para os CIEPs, implantados sob iniciativa de Darcy Ribeiro no Rio de Janeiro durante as gestões de Leonel Brizola (1983-1986) e (1991-1994) (GOMES, LÔBO, FERRAZZO, 2016).

Em uma breve síntese, é possível afirmar que os CIEPs foram implementados como um projeto de escola de período integral com os propósitos de atender a infância. As unidades foram construídas preferencialmente nas regiões habitadas por trabalhadores de baixa renda, projetadas para funcionarem em turno integral, com atividades curriculares, orientação pedagógica, esportes, eventos culturais e alimentação. A proposta apresentada nos documentos oficiais pautava-se, pelo regime de turno único, com funções pedagógicas e sociais ampliadas. Idealizado e coordenado por Darcy Ribeiro, o projeto era tributário da obra de Anísio Teixeira.

Além dos CIEPs, a experiência dos Centros Educacionais Unificados (CEUs), instituída por Decreto Municipal em São Paulo (2001-2004), se fez presente do debate da educação integral, ao propor como objetivo a articulação do atendimento de creche, educação infantil, o desenvolvimento de atividades educativas, culturais e de lazer, em um mesmo espaço físico, com a ideia de que os centros se organizassem em experiências de convívio da comunidade. 
Há que se notar também, que a ampliação da jornada escolar vincula-se ao cenário das reformas educacionais em nosso país e na América Latina, observadas a partir do último decênio do século XX, quando o discurso liberal mais uma vez utilizava a educação como instrumento estratégico para a superação da crise.

No cenário marcado pela crise do "socialismo real", a Conferência Mundial de Educação para Todos (DECLARAÇÃO, 1990), ocorrida em Jomtien, Tailândia, em 1990, é apontada como um marco para o desencadeamento das reformas ocorridas no âmbito da educação, ao indicar proposições às nações consideradas em desenvolvimento. Em um cenário marcado pelo fim do "socialismo real" e de hegemonia do pensamento liberal, a educação era apresentada por muitos intelectuais como instrumento de "equalização" das oportunidades. Não por acaso, o Estado buscou adequar a educação aos preceitos da "nova ordem", que não deixou de ser burguesa.

No Brasil, o esforço para cumprir o acordo firmado em Jomtien (também ratificado por outros documentos internacionais) visou essencialmente à universalização da Educação Básica, à melhoria dos resultados da aprendizagem por meio da satisfação das necessidades básicas de aprendizagem, à redução dos índices de analfabetismo de adultos e à ampliação geral dos serviços de Educação Básica para a formação de outras competências necessárias. As reformas que se seguiram foram amplamente justificadas pela noção de que seria preciso buscar soluções para o ensino público brasileiro, cujo fracasso era expresso em taxas de evasão, repetência e distorção idade-série (MIRANDA; SANTOS, 2012, p. 1075).

No cenário dos anos 1990 e no primeiro decênio do século XXI, observa-se uma série de ações com o propósito declarado de melhorar os índices de escolarização de forma a atender os organismos internacionais. Miranda e Santos (2012) destacam o Bolsa-Escola, a criação do Fundo de Manutenção e Desenvolvimento do Ensino Fundamental e Valorização do Magistério (Fundef), o Programa Nacional do Livro Didático, os Parâmetros Curriculares Nacionais (PCNs), os sistemas de avaliação da Educação Básica e o Programa Dinheiro Direto na Escola. 
Diante das exigências colocadas e da necessidade de dar uma resposta para a crise estrutural que afetava fundamentalmente as classes populares, surgiram projetos que se apresentavam como "novos", com propostas pedagógicas alicerçadas no discurso culturalista e pós moderno, além da defesa de ampliação da jornada escolar. De tal modo, verificou-se que Estados e municípios brasileiros promoveram reformas em seus respectivos sistemas de ensino com distintas ações: progressão continuada, organização em ciclos de formação e ampliação da jornada, denominada por genericamente como educação integral.

Diante do que foi exposto, não buscamos questionar a ampliação da jornada escolar ou das funções da escola, mas analisar as bases que fundamentam esse processo. Em um cenário marcado pela omissão do Estado em prover as condições básicas para o funcionamento da educação, faz-se necessário verificar como a educação integral se materializa nas escolas.

\section{A PROPOSTA DO PROGRAMA MAIS EDUCAÇÃO EM MARINGÁ E A PERCEPÇÃO DE PROFESSORES DE ESCOLAS MANTIDAS PELO MUNICÍPIO}

Diante da exposição realizada anteriormente e dos documentos inventariados para este trabalho, verifica-se que o senso comum identifica a extensão da jornada escolar ou período integral nas escolas com as propostas de educação integral. Isso pode ser identificado inclusive nos documentos norteadores.

No Plano Nacional de Educação de 2014, encontramos:

Meta 6: oferecer educação em tempo integral em, no mínimo, cinquenta por cento das escolas públicas, de forma a atender, pelo menos, vinte e cinco por cento dos(as) alunos(as) da educação básica. (...)

6.5. estimular a oferta de atividades voltadas à ampliação da jornada escolar de alunos(as) matriculados nas escolas da rede pública de educação básica por parte das entidades privadas de serviço social vinculadas ao sistema sindical, de forma concomitante e em articulação com a rede pública de ensino;

$(\ldots)$

6.9. adotar medidas para otimizar o tempo de permanência dos alunos na escola, direcionando a expansão da jornada para 0 
efetivo trabalho escolar, combinado com atividades recreativas, esportivas e culturais (BRASIL, 2014).

Destacamos que o Plano Nacional de Educação aponta para o objetivo de oferecer "educação em tempo integral", com atividades voltadas à ampliação da jornada escolar", adotando medidas que propiciem a "expansão da jornada para o efetivo trabalho escolar".

Isto posto, em função das deliberações legais e, fundamentalmente, considerando as demandas sociais, a ampliação do tempo escolar tem sido compreendida como um elemento de uma educação de qualidade, de formação integral dos alunos e de redução dos efeitos das crises sociais sobre os indivíduos.

Na impossibilidade de ampliar o atendimento em horário integral até hoje considerado um privilégio pelo investimento que envolve muitas redes municipais vêm oferecendo atividades extraclasses que representam algumas horas a mais na escola. Em algumas redes, permite-se que alunos do ensino fundamental frequentem os dois turnos escolares, numa forma precária e improvisada de oferta de horário integral (CASTRO e FARIA, 2002, p. 85).

Como buscamos evidenciar acima, a Educação Integral pode ser "traduzida" de diferentes formas, mas o que tem ocorrido de forma sistemática é sua associação com a ampliação do tempo escolar. Na publicação Percursos da Educação Integral, ao abordar a educação integral em Maringá, encontramos algumas afirmações:

A proposta de educação integral deve ser única para toda a rede, qualquer que seja o programa de ampliação de jornada adotado (...). É importante que as escolas que ainda não têm tempo ampliado conheçam e compreendam a proposta de educação integral elaborada para o município (LOMONACO; SILVA, 2013, p. 141-142) (grifo nosso).

A imprecisão conceitual sobre a educação integral reforça a tendência de predominar a ideia da ampliação da jornada escolar, a oferta de oficinas socioeducativas e o reforço escolar como seu sinônimo. Por isso, salta aos olhos o seguinte questionamento: trata-se de expansão da jornada escolar ou de um projeto de educação integral? 
Além desses aspectos, é notório que o projeto demanda a necessidade de adequação da estrutura física nas escolas para a permanência dos alunos em "tempo integral", o que não implica necessariamente em algo novo, como pode-se perceber pelo histórico das proposições a respeito do tema e em estudos já realizados.

Enquanto proposta curricular, o Programa Mais Educação aproveita as mais variadas propostas do que chamam de educação integral, mas a inexistência de um projeto estrutural de educação integral e a insuficiência de recursos financeiros são pontos de estrangulamento de qualquer inovação mais progressista (MACIEL, JACOMELI, BRASILEIRO, 2017, p. 477) (grifo nosso).

A ausência de esclarecimentos precisos sobre o conceito de educação integral também pode ser observada na "Educação Integral em Maringá", publicação da Secretaria de Educação de Maringá com o apoio técnico da CENPEC (Centro de Estudos e Pesquisas em Educação, Cultura e Ação Comunitária) e Fundação Itaú Social:

\begin{abstract}
Essas formações resultam na constituição do Grupo de Trabalho da Secretária Municipal de Educação, com representantes de cada segmento, para assegurar um processo compartilhado e democrático, na construção das Diretrizes para a Educação Integral, embasados na Pedagogia Histórico-Crítica, na Psicologia HistóricoCultural e no Materialismo Histórico Dialético (...)

A discussão sobre a Educação Integral como resultado e processo de formação da pessoa humana na sua totalidade vem sendo recorrente na história da educação, pois desde a primeira metade do século XX é possível encontrarmos experiências de Educação Integral. Em tais merecem destaque as propostas de Anísio Teixeira que afirmava que só haveria democracia no Brasil no dia que se montasse no país a máquina que a prepararia, a escola pública.

Os estudos de Paulo Freire e Darcy Ribeiro também compõem as matrizes teóricas da Educação Integral que defendem ambiciosamente integrada e integradora, com 0 desafio da transformação social (PINTO, s/d, p. 7-10).
\end{abstract}

Como se vê, trata-se de um eclético caldo ideológico, senão vejamos: como conciliar proposições epistemológicas alicerçadas no materialismo histórico e dialético com o pragmatismo de Anísio Teixeira? E diga-se, não se trata de um fenômeno isolado, mas de uma tendência presente nas formulações de inúmeros programas no campo da educação. 
Observe-se, por exemplo, as diretrizes presentes para Maringá:

3. Explorar novos espaços na ação educativa, legitimando saberes da comunidade e da cidade.

4. Desenvolver, além dos saberes científicos, valores, atitudes e comportamentos. (...)

7. Oferecer vagas para as oficinas pedagógicas, de no mínimo 15 alunos e de no máximo 30 alunos (PINTO, s/d, p. 14) (grifo nosso).

Ora, como afirma Saviani (2003, p. 14), a escola diz respeito à transmissão do conhecimento elaborado e não ao conhecimento espontâneo; ao saber sistematizado e não ao saber fragmentado; à cultura erudita e não à cultura popular. No entanto, o documento produzido orienta uma prática que contraria a proposição da Pedagogia Histórico-Crítica que supostamente fundamenta a Educação Integral em Maringá. Afinal, os "saberes da comunidade" podem ser considerados científicos?

[...] a opinião, o conhecimento que produz palpites, não justifica a existência da escola. Do mesmo modo, a sabedoria baseada na experiência de vida dispensa e até mesmo desdenha a experiência escolar, o que inclusive, chegou a cristalizar-se em ditos populares como: "mais vale a prática do que a gramática" e "as crianças aprendem apesar da escola". E a exigência de apropriação do conhecimento sistematizado por parte das novas gerações que torna necessária a existência da escola (SAVIANI, 2003, p. 15).

Se a referência é a Pedagogia Histórico-Crítica, tal qual aponta o documento "Educação Integral em Maringá", é importante ressaltar que publicações patrocinadas pelo MEC, que são referências para o município, pautam-se por uma orientação oposta. Assim, verifica-se o ecletismo pedagógico.

A instituição escolar é desafiada a reconhecer os saberes da comunidade, para, com eles, promover uma constante e fértil transformação tanto dos conteúdos escolares quanto da vida social. A relação escola e comunidade pode ser marcada pela experiência de diálogo, de trocas, de construção de saberes e pela possibilidade de, juntas, formarem uma comunidade de aprendizagem (MOLL, 2011 , p. 26) (grifo nosso). 
Percebe-se ao longo das propostas presentes em diferentes documentos que orientam o Programa Mais Educação uma mesma tônica: a negação daquilo que chamam "educação tradicional". Trata-se, em outras palavras, da negação daquilo que é classificado como escola tradicional, suas práticas e seus conteúdos clássicos.

Em uma breve síntese, é possível afirmar que as ideias hegemônicas presentes na educação, e igualmente no Programa Mais Educação, assumem o caráter dado essencialmente pelo cenário ideológico no qual predomina uma visão de mundo pós-moderna acrescida de elementos neoliberais quase nunca admitidos como tal.

Outro aspecto a ser enfatizado presente no ideário marcado pelo ecletismo e pelas perspectivas pós modernas traduzem-se no relativismo, que compreende o conhecimento como uma construção a partir do qual o sujeito busca compreender os fenômenos naturais e sociais.

O programa Mais Educação propõe uma metodologia de trabalho capaz de fazer dos programas de governo que integram esta ação um instrumento sensível de produção de conhecimento e cultura, pois considera a diversidade dos saberes que compõem a realidade social brasileira. Sendo assim, essa metodologia não pretende apresentar um modelo; ao contrário, quer compor diversos modelos porque nasce da riqueza de saberes existentes no Brasil. Esta proposta possui, naturalmente, uma estrutura que a fundamenta, mas pretende-se aberta, mutável, capaz de assumir vários contornos e refletir as vocações e experiências comunitárias, frente às principais questões de estudantes brasileiros. Tal intenção desafia a todos nós envolvidos porque exige profissionais atentos para a necessidade de constantemente redesenhá-la.

A metodologia para educação integral apresentada aqui pode ser compreendida como um instrumento de diálogo e troca entre os saberes de escolas e comunidades. Acreditamos que as escolas no Brasil só têm a ganhar se buscarem se abrir para as vivências comunitárias, assim como as comunidades para suas escolas; dessa forma, esperamos poder formular saberes diferenciados, ou seja, saberes diferentes dos originais. Queremos uma educação integral em que as diferenças e saberes possam desenvolver condições de mútuas influências e negociações sucessivas. Uma educação integral estruturada a partir de um conceito de integralidade, que supere termos como "contraturno" e "atividades complementares", bem como saberes escolares e saberes comunitários (MOLL, 2009, p. 13-14). 
Diante dessa indefinição, não é estranho a referência ao cotidiano dos alunos para as atividades escolares. "Em relação direta com a vida estão os saberes que têm origem no fazer, que têm a experiência como grande fonte" (MOLL, 2009, p. 27). Em outras palavras, os conteúdos devem ser pautados na relevância e utilidade prática dos problemas cotidianos. Assim, um dos desdobramentos mais cruéis da transmissão do conhecimento condicionado à sua utilidade na prática cotidiana é o de contribuir para o esvaziamento da escola como instituição de transmissão dos conhecimentos historicamente produzidos pela humanidade.

Nesse aspecto, podemos afirmar que o respeito ao cotidiano ou a liberdade dos alunos em uma sociedade marcada pelo antagonismo de classes significa renunciar e a opor qualquer resistência às influências sociais. Observe-se, por exemplo, as contribuições de Duarte sobre o tema:

\begin{abstract}
Se o conhecimento mais valorizado na escola passa a ser o conhecimento tácito, cotidiano, pessoal, então o trabalho do professor deixa de ser o de transmitir os conhecimentos mais desenvolvidos e ricos que a humanidade venha construindo ao longo de sua história. O professor deixa de ser um mediador entre o aluno e o patrimônio intelectual mais elevado da humanidade, para ser um organizador de atividades que promovam o que alguns chamam de negociação de significados construídos no cotidiano dos alunos (DUARTE, 2010, p. 38).
\end{abstract}

Como se vê, as proposições pós modernas, denunciadas por Duarte e presentes no Programa Mais Educação, impõe-se ao professor tarefas que contribuem para o empobrecimento do trabalho docente. Não por acaso, a formação dos professores segue em linhas gerais a mesma diretriz. $O$ conhecimento sistematizado perde espaço para a resolução dos problemas cotidianos.

Na publicação "Educação Integral em Maringá", encontramos a aproximação com as proposições relativistas presentes nos documentos do Ministério da Educação.

Na prática docente, os professores adaptam, recriam, refazem, ressignificam seus saberes de formação acadêmica, para 0 enfrentamento do cotidiano escolar que nos desafia a problematizar 
criticamente a realidade, assumindo o compromisso de formar seres humanos. Para que esse compromisso tenha êxito, temos que formar docentes reflexivos, críticos, investigadores, pesquisadores, despertando, assim a permanente curiosidade diante do novo (PINTO, s/d, p. 32) (grifo nosso).

Segundo Duarte (2010, p. 41), a perspectiva do professor reflexivo nada mais é do que a aplicação, à formação de professores, das ideias escolanovistas, construtivistas e do princípio da centralidade do conhecimento tácito. Nesse processo a experiência é avaliada como fonte do saber, porque é por meio dela que se edifica o saber profissional. Dessa forma, se os alunos necessitam construir seus conhecimentos a partir das demandas do cotidiano. Assim, a formação dos professores também deve ser orientada pela mesma diretriz, pois o conhecimento necessário para a tomada de decisões não é proveniente da teoria, mas das ações cotidianas. O papel do professor incide mais em "facilitar" a aprendizagem, em ajudar a "aprender a aprender".

Como decorrência da hegemonia das pedagogias relativas, como se observa no Programa Mais Educação, incentivam-se explicações simplistas e se adotam ideias desvinculadas da realidade material que forjam a educação escolar. O fetichismo da proposta é mais importante que reconhecer a existência de problemas como a pobreza e as desigualdades sociais.

No entanto, o fetichismo dos saberes cotidianos não constituem no único problema a ser enfrentado. Verifica-se igualmente a privatização das responsabilidades de manutenção da estrutura escolar.

Muitas vezes, a escola tem uma sala onde são deixadas somente as caixas com os materiais que o MEC envia! Os manuais, os livros, os jogos devem chegar nas mãos de quem precisa deles. Vamos lá, professora! Distribua os materiais! Faça uma estante e ponha os livros no canto da sala que vira um projeto de biblioteca! Esvazie a sala e tenha um espaço a mais para as atividades de Educação Integral! Em outros lugares há salas com entulhos: cadeiras e mesas quebradas, matérias ultrapassadas, caixas com atas e registros antigos É preciso arejar estes espaços e ressignificá-los.

No pátio podem ser colocadas mesas para os jogos de xadrez e tênis de mesa. Em alguns lugares, as escolas colocaram toldos/ pequenas coberturas que vêm permitindo atividades de teatro, de dança, 
jornal escolar, entre outros. Enfim o desafio que está posto é de redescobrir a escola e seu entorno, ressignificando seus espaços! (MOLL, 2011, p. 22-23) (Grifos nossos).

Como contraponto as ideias defendidas por Moll, é importante destacar a dimensão política da proposta ancorada em uma perspectiva idealista, fundamentando-se nos desafios colocados pela prática aos professores. Assim, cabe ao professor fazer "uma estante", reorganizar "salas com entulhos: cadeiras e mesas quebradas, matérias ultrapassadas, caixas com atas e registros antigos É preciso arejar estes espaços e ressignificá-los". Tudo se passa como se o professor não estivesse sobrecarregado de atividades.

É pertinente defender que o sistema escolar transfere ao profissional a responsabilidade de cobrir as lacunas existentes na instituição, a qual estabelece mecanismos rígidos e redundantes de avaliação e contrata um efetivo insuficiente, entre outros (GASPARINI; BARRETO; ASSUNÇÃO, 2005, p. 191).

Diante dos problemas sociais cada vez mais agudos, acrescidos das condições nem sempre adequadas de funcionamento do prédio escolar, Moll (2011) aponta para soluções legitimadoras da omissão do Estado no papel de provedor da educação pública. Não por acaso, a boa vontade dos professores em "ressignificar" os espaços da escola levarão à superação dos problemas.

Observe-se agora, a compreensão de seis (06) professores e um (01) coordenador pedagógico de escolas de Maringá, que obviamente apresentam uma série de restrições, entre as quais, o número de amostragem restrito de professores participantes da pesquisa, ainda em estágio inicial. Entretanto, se a tarefa é complexa e demanda um tempo maior, há que se analisar os levantamentos preliminares e as hipóteses acerca dos problemas presentes no Programa Mais Educação.

Os dados coletados por meio de entrevistas e documentos oficiais apontam para a existência de um projeto de ampliação da jornada escolar, com novas atribuições à escola, além do desconhecimento entre professores sobre o significado da proposta. 
As respostas, que analisaremos a seguir, não devem ser entendidas de forma isolada, mas como manifestações das condições reais de produção da escola mantida pelo Estado na sociedade contemporânea. Isto posto, os processos de construção do programa, a formação dos professores e as condições materiais e espaciais da escola inserem-se em um quadro de omissão do Estado para as questões sociais, além do fato que os serviços públicos, incluindo a educação, foram historicamente limitados e seletivos.

Quadro 1 - Concepção sobre Educação Integral

\begin{tabular}{|l|l|}
\hline Professores/Escola & Qual a sua concepção sobre Educação Integral? \\
\hline Professor 1/Escola 1. & $\begin{array}{l}\text { Educação Integral do meu ponto de vista e com as poucas } \\
\text { leituras que tenho do assunto, seria aquela educação que } \\
\text { visa desenvolver o aluno em seu todo, ou seja, aspecto } \\
\text { cognitivo, linguagem, raciocínio lógico, entre outras. } \\
\text { Portanto não seria uma ampliação da jornada escolar. }\end{array}$ \\
\hline Professor 2/ Escola 1 & $\begin{array}{l}\text { Eu enquanto professora não concordo com o Programa } \\
\text { Mais Educação da forma como está sendo executado. As } \\
\text { crianças passam a maior parte do tempo em sala de aula, } \\
\text { acho muito cansativo, pois os conteúdos não são atrativos } \\
\text { e quando vem algo diferente não tem material para } \\
\text { confeccionar. Lembrando que a criança absorve 33\% do } \\
\text { conteúdo por dia. }\end{array}$ \\
\hline Professor 1/ Escola 2 & $\begin{array}{l}\text { Um ensino no qual os alunos permanecem o dia todo na } \\
\text { escola. E nesse período sejam executadas atividades } \\
\text { voltadas ao conteúdo pedagógico pela manhã, e a tarde } \\
\text { realização de oficinas voltadas à educação lúdica. }\end{array}$ \\
\hline Professor 4/Escola 3 & $\begin{array}{l}\text { Acredito que se fosse organizada com atividades lúdicas, } \\
\text { que tirassem o aluno da sala de aula, seria muito boa. Mas } \\
\text { da forma que está sendo trabalhada acaba se tornando } \\
\text { exaustiva. }\end{array}$ \\
\hline
\end{tabular}

Fonte: Pinheiro (2017).

Como se nota, não há um rigor teórico na compreensão da proposta, evidenciando um fenômeno já apontado em outros trabalhos, tais como Gomes, Lôbo e Gedeli (2016) ou Maciel, Jacomeli, Brasileiro (2017). Os trabalhos citados e a pequena amostragem preliminar da presente pesquisa apontaram para a fragilidade sobre a compreensão dos preceitos acerca da educação integral e a existência de diferenças significativas em relação as concepções. 
Assim, ampliar o tempo escolar implica na materialização da educação integral? As aulas do contraturno escolar podem ser consideradas como elementos de uma educação integral?

Quadro 2 - Atividades de reforço escolar do Programa Mais Educação

\begin{tabular}{|lr|l|}
\hline $\begin{array}{l}\text { Professores/ } \\
\text { Escolas }\end{array}$ & $\begin{array}{l}\text { As atividades de reforço escolar do Programa Mais Educação estão } \\
\text { relacionadas com os conteúdos que você ministra em sala de aula? }\end{array}$ \\
\hline $\begin{array}{l}\text { Professor } \\
\text { Escola 1 }\end{array}$ & l/ & $\begin{array}{l}\text { Não, pois ministro a oficina de artesanato e o reforço é somente de } \\
\text { português. }\end{array}$ \\
\hline $\begin{array}{l}\text { Professor } \\
\text { Escola 1 }\end{array}$ & $2 /$ & Sim, sempre procuramos relacionar para não ficar conteúdo perdido. \\
\hline $\begin{array}{l}\text { Professor } \\
\text { Escola 2 }\end{array}$ & 1/ & $\begin{array}{l}\text { Não, pois na sala de aula há o planejamento geral com poucas } \\
\text { especificidades e no reforço espera-se que ocorra um olhar mais } \\
\text { atento as defasagens dos níveis anteriores. }\end{array}$ \\
\hline $\begin{array}{l}\text { Professor } \\
\text { Escola 3. }\end{array}$ & $1 /$ & $\begin{array}{l}\text { Na escola temos o apoio em contra turno que acredito que não está } \\
\text { relacionado como o Programa Mais Educação. }\end{array}$ \\
\hline
\end{tabular}

Fonte: Pinheiro (2017).

Diferentes estudos confirmam o uso da expressão "educação integral" de forma indiscriminada, quando verdadeiramente são atividades no contraturno escolar sem vínculo orgânico com uma concepção de educação integral enquanto formação "total" do sujeito. Assim, toma-se em diferentes oportunidades o reforço escolar ou as oficinas ofertadas no contraturno como modelo de educação integral.

A possibilidade de trabalhar articuladamente as atividades de turno e contraturno escolar, implica necessariamente na construção e adequação do espaço escolar para o funcionamento das atividades pedagógicas. Caso contrário, veremos apenas a improvisação de atividades que pouco acrescentam na formação do indivíduo.

Quadro 3 - Ampliação do tempo na escola

\begin{tabular}{|l|l|}
\hline $\begin{array}{l}\text { Professores/ } \\
\text { Escolas }\end{array}$ & $\begin{array}{l}\text { Mais tempo na escola possibilita aos alunos, uma quantidade } \\
\text { maior de oportunidades de aprendizagem? }\end{array}$ \\
\hline $\begin{array}{l}\text { Professor 1/ } \\
\text { Escola 1 }\end{array}$ & $\begin{array}{l}\text { Em sua teoria deveria possibilitar, entretanto não é o que } \\
\text { verificamos na prática, pois como já dito, o objetivo seria } \\
\text { desenvolver o aluno de forma integral e o que verificamos é uma } \\
\text { jornada da permanência do aluno na escola ampliada, pois no } \\
\text { período da tarde os alunos estão extremamente cansados e } \\
\text { desmotivados. }\end{array}$ \\
\hline $\begin{array}{l}\text { Professor 2/ } \\
\text { Escola 1 }\end{array}$ & $\begin{array}{l}\text { Deveria possibilitar se a grade curricular oferecesse atividades } \\
\text { diferenciadas como: teatro, atividades físicas, danças, entre }\end{array}$ \\
\hline
\end{tabular}




\begin{tabular}{|l|l|}
\hline & Outros. \\
\hline $\begin{array}{l}\text { Professor 1/ } \\
\text { Escola 2 }\end{array}$ & $\begin{array}{l}\text { Isso é muito variável, pois depende de aluno a aluno. Ao meu ver, } \\
\text { os alunos se sentem muito cansados decorrente ao tempo que } \\
\text { permanece na escola. Há relatos de vários professores que na } \\
\text { parte da tarde (após tido aula de manhã) os alunos não focam } \\
\text { nos seus deveres e ficam mais agitados, pois levam mais a sério o } \\
\text { conteúdo do primeiro período. }\end{array}$ \\
\hline $\begin{array}{l}\text { Professor 1/ } \\
\text { Escola 3. }\end{array}$ & $\begin{array}{l}\text { Acredito que não, porque o que posso perceber são alunos } \\
\text { exaustos, desmotivados e isso tem gerado muita indisciplina o que } \\
\text { tem prejudicado na aprendizagem dos alunos. }\end{array}$ \\
\hline
\end{tabular}

Fonte: Pinheiro (2017).

Ora, como se vê a partir das respostas, a ampliação do tempo escolar não possui uma relação direta com a qualidade da aprendizagem, já que necessita considerar também outros fatores. Ainda que consideremos o início da presente pesquisa e seus resultados parciais, as respostas indicam que não ocorreu a qualificação do ensino. Este fenômeno é o desdobramento da falta de estrutura adequada para realizar o que se propõe: a formação integral do aluno.

Schlesener (2009, p. 169), aponta que "desde a década de 90, percebe-se a queda da qualidade do ensino, que pode ser atribuída à expansão do sistema acompanhada de restrição de investimentos". Assim, não se trata aqui, de descartar a ampliação do tempo escolar, mas de questionar a forma como ocorre e a organização das atividades no contraturno escolar em um cenário marcado pela falta de profissionais e materiais pedagógicos, que não podem ser desvinculados da pobreza material que verifica-se no "chão da escola".

Quadro 4 - Formação para o Programa Mais Educação

\begin{tabular}{|l|l|}
\hline $\begin{array}{l}\text { Professores/ } \\
\text { Escolas }\end{array}$ & Há alguma formação para o Programa Mais Educação? \\
\hline $\begin{array}{l}\text { Professor 1/ } \\
\text { Escola 1 }\end{array}$ & $\begin{array}{l}\text { Sim, somente recentemente houve formação para a oficina que } \\
\text { ministro (foi a primeira deste ano), porém para as professoras } \\
\text { regentes de oficina de português e matemática ocorre todo mês. }\end{array}$ \\
\hline $\begin{array}{l}\text { Professor 2/ } \\
\text { Escola 1 }\end{array}$ & Sim, tudo repetitivo, nada inovador. \\
\hline $\begin{array}{l}\text { Professor 1/ } \\
\text { Escola 1 }\end{array}$ & Não. \\
\hline P1/ Escola 3. & $\begin{array}{l}\text { Não sei responder ao certo, mas as professoras da tarde têm } \\
\text { participado de formações junto a SEDUC. }\end{array}$ \\
\hline
\end{tabular}

Fonte: Pinheiro (2017). 
O quadro acima sugere uma formação desvinculada dos fundamentos da educação integral, caracterizando-se por uma atuação sem o planejamento adequado com atividades que objetivam o preenchimento do tempo. Dessa forma, o que se nota é um conjunto de ações paliativas que não alteram, e nem poderiam, as estruturas essenciais do que vem ocorrendo no âmbito educacional.

Deve-se ressaltar que, mesmo quando as propostas anunciam a produção de um "novo" tipo de escola a partir da adoção do tempo integral, muitas experiências podem ser consideradas como adaptações das escolas regulares. Ainda que possam desenvolver aspectos diferenciados, essas propostas não rompem com a organização da escola pública brasileira e não constituem, em si mesmas, inovações quanto à forma ou ao conteúdo (MIRANDA; SANTOS, 2012, p. 1085).

Tal qual os apontamentos de Miranda e Santos (2012), verifica-se que prevalece a proposição de ações caracterizadas pela descontinuidade e sem bases científicas, tal qual ocorre com os oficineiros, que não precisam ter licenciatura em alguma área. Acrescente-se que as atividades desenvolvidas com oficinas nem sempre são realizadas por professoras, mas com alunos de graduação que não possuem garantias de remuneração ao longo do ano letivo, tal qual atesta o Requerimento $N^{\circ} 728 / 2015$, do então vereador Ulisses Maia, de 14 de julho de 2015, que solicitava informações da data para "a cessação da remuneração dos referidos oficineiros, bem como se a remuneração dos oficineiros está garantida até o final do corrente ano".

\section{Quadro 5 - Coordenação pedagógica}

\begin{tabular}{|l|l|}
\hline Coordenação pedagógica/ Escola Al & \multicolumn{1}{|c|}{ Educação Integral só será } \\
1- Qual a sua concepção sobre & $\begin{array}{l}\text { E efetivamente funcional quando o ensino } \\
\text { fundamental for a base para todo o } \\
\text { processo educacional, não podemos } \\
\text { achar que a Educação Integral será o } \\
\text { remédio para as mazelas educacionais, } \\
\text { pois de nada adianta prolongar o tempo } \\
\text { na escola e a qualidade continuar a } \\
\text { mesma, na atualidade temos um } \\
\text { modelo que pode ser reformulado e } \\
\text { repensado como Educação Integral e } \\
\text { não apenas escola em tempo integral. }\end{array}$ \\
\hline
\end{tabular}




\begin{tabular}{|c|c|}
\hline $\begin{array}{l}2 \text { - A estrutura física da escola está } \\
\text { adequada para a Educação Integral? }\end{array}$ & $\begin{array}{l}\text { Ainda não pois todas as escolas são } \\
\text { construídas para dois padrões de } \\
\text { educação em dois horários e com } \\
\text { clientelas diferentes e até mesmo outro } \\
\text { corpo docente. }\end{array}$ \\
\hline $\begin{array}{l}3 \text { - Quais atividades do Programa Mais } \\
\text { Educação estão disponibilizadas para os } \\
\text { alunos no contraturno? }\end{array}$ & $\begin{array}{l}\text { Artesanato, música, jogos e brincadeiras, } \\
\text { atletismo, português e matemática. }\end{array}$ \\
\hline $\begin{array}{l}4 \text { - Quem é responsável por essas } \\
\text { atividades? }\end{array}$ & $\begin{array}{l}\text { Professores e educadores com o apoio } \\
\text { de estagiários. }\end{array}$ \\
\hline $\begin{array}{l}5 \text { - Quem se encarrega de observar e } \\
\text { acompanhar as diversificadas atividades } \\
\text { do Programa Mais Educação? }\end{array}$ & $\begin{array}{l}\text { Equipe diretiva da escola e os órgãos } \\
\text { competentes. }\end{array}$ \\
\hline $\begin{array}{l}6 \text { - É possível notar alguma mudança nos } \\
\text { alunos em relação ao desenvolvimento } \\
\text { cognitivo? Quais? }\end{array}$ & $\begin{array}{l}\text { O desenvolvimento se dá de maneira } \\
\text { bastante individual, temos alunos que } \\
\text { realizam atividades com muito } \\
\text { empenho, esses sim progridem, porém } \\
\text { temos aqueles que não se adaptam a } \\
\text { ficam na escola se sentindo "obrigados". } \\
\text { Os que valorizam as atividades passam } \\
\text { por modificações significativas na } \\
\text { aprendizagem e no âmbito pessoal. }\end{array}$ \\
\hline $\begin{array}{l}7 \text { - Mais tempo na escola possibilita aos } \\
\text { alunos, uma quantidade maior de } \\
\text { oportunidades de aprendizagem? }\end{array}$ & $\begin{array}{l}\text { As possibilidades existem, porém nem } \\
\text { sempre são bem aproveitadas pelos } \\
\text { alunos, principalmente os que possuem } \\
\text { dificuldade de aprendizagem. }\end{array}$ \\
\hline $\begin{array}{l}8 \text { - Como está sendo operacionalizado } \\
\text { as atividades do turno parcial e as } \\
\text { atividades do contraturno? }\end{array}$ & $\begin{array}{l}\text { Durante a manhã são trabalhados os } \\
\text { conteúdos básicos e no contraturno está } \\
\text { sendo trabalhado as dificuldades mais } \\
\text { acentuadas. }\end{array}$ \\
\hline $\begin{array}{l}9 \text { - Há alguma formação para o } \\
\text { Programa Mais Educação? }\end{array}$ & Sim. \\
\hline $\begin{array}{l}10 \text { - Você participou de alguma } \\
\text { formação sobre o Programa Mais } \\
\text { Educação? }\end{array}$ & Sim. \\
\hline $\begin{array}{l}11 \text { - Você já participou de atividades } \\
\text { relacionadas ao Programa Mais } \\
\text { Educação? }\end{array}$ & sim. \\
\hline
\end{tabular}

Fonte: Pinheiro (2017).

As respostas elencadas acerca do desenvolvimento da educação integral e da ampliação do tempo escolar expõem as fragilidades e os impasses de uma proposta que, independente disso, tem sido apresentada pelo poder público como uma solução para problemas educacionais e sociais.

Quanto as possibilidades de aprendizagem, verifica-se, por exemplo, segundo a equipe pedagógica que "existem, porém, nem sempre são bem 
aproveitadas pelos alunos", discurso que coaduna-se com a retórica neoliberal de privatização do sucesso ou fracasso do indivíduo. Assim, a educação escolar assume o discurso da produção de homens adaptados à lógica do mercado.

A sociedade moderna está submetida ao crivo do modelo capitalista de produção e, seguindo esta lógica, a escola também se submete a este crivo. Logo, a política que regula esse modelo econômico estende seus tentáculos para o interior da escola, influenciando, diretamente, o processo educacional e a construção dos diversos modelos curriculares. A escola passa, então, a funcionar como caixa de ressonância dos anseios das elites detentoras do poder político e econômico que fazem a gestão do atual modelo econômico (FONSECA, 2012, p. 6).

Dessa forma, o que será ensinado e o como será é perpassado pelos interesses do capital e do Estado que o representa. Apresentando-se como instituição acima dos interesses de classe, O Estado indica caminhos supostamente democráticos para a constituição da "educação integral" com um discurso carregado de expressões como "igualdade", "cidadania", "democracia", "participação", "comunidade" etc. No entanto, são ideias desvinculadas da base material no qual assenta-se as relações de classe.

Por trás do discurso "democrático" encontra-se a tendência de distorcer o conceito de educação integral para ofertar a ampliação da jornada escolar precarizada como elemento de democratização da educação.

\section{CONSIDERAÇÕES FINAIS}

O presente trabalho buscou analisar, a partir da disseminação da proposta de educação integral em Maringá, alguns elementos de reflexão sobre as lacunas presentes no Programa Mais Educação, levando em consideração os limites materiais presentes em uma sociedade dividida em classes sociais.

Nos marcos em que ocorreu o desenvolvimento do Programa Mais Educação, percebe-se sua convergência dos propósitos dos organismos internacionais com o atendimento de demandas populares por educação. 
Não por acaso, a leitura dos documentos balizadores do Programa Mais Educação revela a indeterminação do que seria a "formação integral" do educando ao mesmo tempo em que apontam para a responsabilização da comunidade escolar em um claro movimento de omissão do Estado no provimento de recursos necessários.

Por isso, a Educação Integral continua no campo das intenções. Não basta a escola inserir uma diversidade de atividades no período do contraturno sem o devido planejamento ou condições de realização. Por isso, o questionamento inicial: quais os caminhos norteadores que balizam a educação integral proposta no programa? se as propostas são caracterizadas pela indeterminação conceitual, como pode-se observar nos documentos, como desenvolver o educando em suas múltiplas dimensões sem uma ação consciente e deliberada da escola?

A Educação em Tempo Integral exige mais do que proclamações oficiais e "desafios" propostos aos professores. É necessário um projeto pedagógico coerente com o propósito de emancipação humana, formação sólida de seus agentes, infraestrutura adequada, além é claro, de recursos disponibilizados para sua materialização. Trata-se de pensarmos uma escola comprometida com os interesses dos trabalhadores e seus filhos, que possibilite o acesso ao conhecimento produzido historicamente pela humanidade e contribua verdadeiramente para a emancipação humana.

\section{REFERÊNCIAS}

BRASIL, Ministério da Educação. Lei 13005 de 25 de junho de 2014. Aprova o Plano Nacional de Educação - PNE e dá outras providências. Diário Oficial da União. Brasília, 2014, p. 2-7. Disponível em: http://www2.camara.leg.br/legin/fed/lei/2014/lei-13005-25-junho-2014778970-publicacaooriginal-144468-pl.html. Acesso em: 2 fev. 2015.

BRASIL, SEB/MEC. Programa Mais Educação: passo a passo, 2011.

CARONE, E. Movimento Operário no Brasil: 1877-1944. 2ª ed. São Paulo: DIFEL, 1984.

CASTANHA, A. P. Retornar às fontes: desafios aos estudos históricoeducativos. In: SILVA, J. C. da, ORSO, P. J.; CASTANHA, A. P.; MAGALHÃES, L. 
D. R. (Orgs.). História da Educação: arquivos, instituições escolares e memória história. Campinas: Alínea, 2013.

CASTRO, A. R. V. de; FARIA, L. C. M. de. CIEP: o resgate da utopia. In: COELHO, L. M. C; CAVALIERE, A. M. (Orgs.). Educação brasileira e(m) tempo integral. Petrópolis, RJ: Vozes, 2002, p. 133-146.

CAVALIERE, A. M. Anísio Teixeira e a educação integral. Paidéia, vol. 20, n 46 , Ribeirão Preto, 2010.

DECLARAÇÃO MUNDIAL SOBRE EDUCAÇÃO PARA TODOS. Jomtien, Tailândia, 1990.

DUARTE, N. O debate contemporâneo das teorias pedagógicas. In: MARTINS, L. M.; DUARTE, N. (Orgs.) Formação de professores: limites contemporâneos e alternativas necessárias. São Paulo: Editora UNESP; São Paulo: Cultura Acadêmica, 2010.

FONSECA, V. M da. O gigante dos pés de barro: capitalismo e desenvolvimento sustentável. Universidade Federal de Uberlândia (UFU). Tese, 2012.

GASPARINI, S. M.; BARRETO, S. M.; ASSUNÇÃO, A. D. O professor, as condições de trabalho e os efeitos sobre sua saúde. Educação e Pesquisa, São Paulo, v. 31, n. 2, p. 189-199, 2005.

GOMES, M. A. O.; LOBO, C. B.; FERRAZZO, G. As formas de materialização das políticas de educação integral em Rondônia. Revista HISTEDBR On-line, Campinas, $n^{\circ}$ 69, p. 100-123, 2016.

LOMONACO, B. P.; SILVA, L. A. M. Percursos da educação integral em busca da qualidade e da equidade. São Paulo: CENPEC. Fundação Itaú Social Unicef, 2013.

MACIEL, A. C.; JACOMELI, M. R. M.; BRASILEIRO, T. S. A. Fundamentos da educação integral politécnica: da teoria à prática. Educação e Sociedade. Campinas, v. 38, n. 139, p.473-488, 2017.

Manifesto dos pioneiros da educação nova. Revista HISTEDBR On-line, Campinas, $n^{\circ}$ especial, p.188-204, ago. 2006.

MARX, K.; ENGELS, F. A ideologia alemã. São Paulo: Hucitec, 1984.

MEC, SECAD. Programa Mais Educação: passo a Passo. Série Mais Educação. Brasilia, 2011. 
MIRANDA, M. G. de; SANTOS, S. V. Propostas de tempo integral: a que se destina a ampliação do tempo escolar? Florianópolis, v. 30, n. 3, 1073-1098, set./dez. 2012.

MOLL, J. (Org.). Caminhos para elaborar uma proposta de Educação Integral em Jornada Ampliada. Brasília: SEB/MEC, 2011.

MOLL, J. Rede de saberes mais educação: pressupostos para projetos pedagógicos de educação integral: caderno para professores e diretores de escolas. - 1. ed. - Brasília: Ministério da Educação, 2009.

MOLL, J. A agenda da educação integral: compromissos para sua consolidação como política pública. In: MOLL, Jaqueline et al. Caminhos da educação integral no Brasil: direito a outros tempos e espaços educativos. Porto Alegre-RS: Penso, 2012.

PINHEIRO, L. I. S. Educação integral: construção histórica e perspectivas contemporâneas nas escolas públicas do município de Maringá.

Universidade Estadual de Maringá. Trabalho de Conclusão de Curso, 2017.

PINTO, A. de F. et. al. Educação integral em Maringá. CENPEC.

SAVIANI, D. Pedagogia histórico-crítica: primeiras aproximações. Campinas: Autores Associados, 2003.

SCHLESENER, A. H. A Escola de Leonardo: Política e Educação nos escritos de Gramsci. Brasília: Líber Livro, 2009.

TEIXEIRA, A. Centro Educacional Carneiro Ribeiro. Revista Brasileira de Estudos Pedagógicos. Rio de Janeiro, v 31, nº 73, p. 78-84, 1959.

Recebido em: Novembro de 2017 Aprovado em: Junho de 2018 